\title{
Attitudes underlying reliance on complementary and alternative medicine
}

\author{
Szilvia Zörgő, Gjalt-Jorn Peters \& Samvel Mkhitaryan
}

This work has been published and is publicly available at the following URL: https://journals.sagepub.com/doi/full/10.1177/1534735420910472

Citation information: 2020 Zörgö, S., Peters, GY, Mkhitaryan, S. Attitudes underlying reliance on complementary and alternative medicine. Integrative Cancer Therapies 19: 1-14. 


\section{Attitudes underlying reliance on complementary and alternative medicine}

Szilvia Zörgő, Gjalt-Jorn Peters \& Samvel Mkhitaryan

This document is the full text of the article "Attitudes underlying reliance on complementary and alternative medicine", which is under review at the journal Integrative Cancer Therapies.

The most current version of this manuscript is hosted at PsyArXiv (see

doi.org/10.31234/osf.io/tg42a) - please check the most recent version of the preprint before citing this article.

All data, materials, and scripts are available at the Open Science Framework and the GitLab repository, enabling researchers to inspect the exact correlation coefficients and confidence intervals, conduct alternative analyses, or include the data in individual patient data metaanalyses.

This preprint is licensed under:

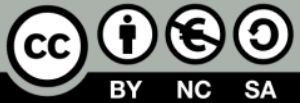




\section{Attitudes underlying reliance on complementary and alternative medicine}

\section{Introduction}

In Western pluralistic healthcare systems, patients have the option of choosing "non-conventional treatments" to treat their ailment: services, products, and processes (together: "modalities") referred to as complementary and alternative medicine (CAM). The term "complementary" signifies treatments that are used in tandem with biomedicine, whereas the term "alternative" connotes treatments employed instead of biomedicine. Most studies agree that CAM use is increasing throughout the Western world (Frass et al., 2012; Thomas, Nicholl, \& Coleman, 2001; Tindle, Davis, Phillips, \& Eisenberg, 2005), and depending on the scrutinized illnesses and modalities, ranges between $40-86 \%$ in the United States and Europe (Arthur et al., 2012; Eardley et al., 2012).

Although CAM use in many cases does not endanger the patient, there are instances when nonconventional therapy employed as alternative treatment does signify a hazard. CAM users are at a higher risk of foregoing recommended biomedical treatment either in an a priori (refusal to undergo treatment) or a posteriori (discontinuing the treatment) manner (Zörgő \& Olivas Hernández, 2018). Refusal to undergo or electing to discontinue biomedical treatment when faced with life-threatening illness poses threats to patient safety, as do potentially dangerous interactions among biomedical and CAM therapies (Huiart, Bouhnik, Rey, Rousseau, \& Retornaz, 2013; Seely \& Oneschuk, 2008). This is exacerbated by the fact that 40-77\% of those employing CAM opt not to disclose their CAM use to their physician (Eisenberg et al., 1998; Ernst, 2000; Faith, Thorburn, \& Tippens, 2013; Yates et al., 2005), even in disease types such as cancer (Adler \& Fosket, 1999; Davis, Oh, Butow, Mullan, \& Clarke, 2012; Huiart et al., 2013). When CAM use occurs as an alternative to biomedicine in a life-threatening situation or if it interferes with the effectiveness of biomedicine, we refer to it as "dysfunctional". In such situations, intervention is warranted to prevent needless incidents and mortality, and such intervention requires a thorough understanding of 
the determinants of dysfunctional CAM use (Bartholomew Eldredge et al., 2016; Peters, 2014; Rossi et al., 2017).

The Cochrane Collaboration defines CAM as "[a] broad domain of healing resources that encompasses all health systems, modalities, and practices and their accompanying theories and beliefs, other than those intrinsic to the politically dominant health systems of a particular society or culture in a given historical period" (Wieland, Manheimer, \& Berman, 2011, p. 4). This definition acknowledges that CAM is not restricted to a specific service or product, but encompasses a set of beliefs concerning health and illness as well, which may vary considerably among modalities, yet represent important factors in their use.

Most studies treat CAM users as one group, but when scrutinized separately, patients employing non-conventional treatments in tandem with biomedicine (complementary medicine, $\mathrm{CM}$ ) and those employing them as an alternative to biomedicine (alternative medicine, AM) exhibited different motivations and attitudes. In 1998, Astin found that dissatisfaction with and distrust in biomedicine was a significant predictor in alternative, but not in complementary use (Astin, 1998). In the latter group, patient characteristics such as "holistic thinking" and "spirituality" (Astin, 1998) were significant predictors, alongside psychosocial etiology as a naive theory of illness causation (Farrukh, MakmorBakry, Hatah, \& Tan, 2018). According to Hunt, employing CAM as an alternative to (as opposed to complementing) biomedicine reached 30\% among all British CAM users in 2010 (Hunt et al., 2010).

Many studies have explored sociodemographic variables in connection with CAM use such as age, education, place of residence, economic status, sexual orientation, and religion (Garro, 1998; Stratton \& McGivern-Snofsky, 2008) and have concluded that the average CAM user is a middle-aged, wealthy, welleducated, Caucasian female most likely suffering from cancer (Arthur et al., 2012; Astin, 1998; Ernst, 2000; Faith et al., 2013; P. Harris, 2012; Hunt et al., 2010). However, sociodemographic determinants of behavior cannot feasibly be targeted by interventions aiming to decrease dysfunctional CAM use: such prevention efforts are limited to targeting modifiable determinants, often the proximal determinant of 
behavior that mediate potential effects of more distal sociodemographic determinants (Crutzen \& Peters, 2018; Peters \& Crutzen, 2017).

Studies that addressed more proximal determinants of CAM use explored patient motivations. For example, the market niche hypothesis asserts that CAM appeals to patients in areas where biomedicine is perceived to be lacking: patient-centered care and the attribution of meaning to suffering (Cartwright \& Torr, 2005; Knoll, 2004; Stratton \& McGivern-Snofsky, 2008; Yarney et al., 2013). Another approach is the Push and Pull dichotomy, where motivations for CAM use are grouped into the categories of "push factors" repelling patients from biomedicine (e.g. ineffective cure for their illness or severe side-effects) and "pull factors" drawing patients toward CAM (Bahall, 2015; Kelner \& Wellman, 1997; Lövgren, WildeLarsson, Hök, Leveälahti, \& Tishelman, 2011; Pawluch, Cain, \& Gillett, 2000; Stevinson \& Ernst, 2006). The most prominent pull factor is "philosophical congruence" (Vincent \& Furnham, 1996), which occurs when a patient presumes to discover their own cultural values in a CAM modality, that is, the patient identifies with (aspects of) the modality's cultural system. Such congruence may occur in a wide variety of ways with an assorted constellation of values and attitudes.

Similar to the dichotomic model of Push and Pull, many authors juxtapose "dissatisfaction with biomedicine" on the one hand, and general "values/beliefs" on the other, assigning the latter a more significant role in therapy choice (Astin, 1998; Goldstein, 2002; Siahpush, 1999). A substantial amount of literature on the subject considers such beliefs significant predictors of CAM use, overshadowing the importance of a perceived lack in biomedicine (Arthur et al., 2012; Astin, 1998; Connor, 2004; P. Harris, 2012; O'Callaghan \& Jordan, 2003; Vincent \& Furnham, 1996) or clinical factors (Furnham, 1994; Vincent \& Furnham, 1997). Such general beliefs that have been linked to increased CAM use include a need for more control and empowerment in the illness experience (Arthur et al., 2012; Bann, Sirois, \& Walsh, 2010; Deng, 2008; Kaptchuk, Edwards, \& Eisenberg, 1996; Thorne, Paterson, Russell, \& Schultz, 2002) and in the practitioner-patient relationship (Arthur et al., 2012; Bishop, Yardley, \& Lewith, 2007; Crocetti 
et al., 1998; Eliason, Huebner, \& Marchand, 1999; Singh, Maskarinec, \& Shumay, 2005), as well as a marked need for social support (Arthur et al., 2012; Bishop et al., 2007; Hunt et al., 2010; Stratton \& McGivern-Snofsky, 2008).

Furthermore, illness usually induces a loss of control (Frank, 1993; Pierret, 2003), which may trigger an increased need for attributing meaning to the illness experience (Csordas, 1997). Meaning-making in such a context has been shown to aid disease management, as well as increase the level of perceived control (Arthur et al., 2012; Köteles, 2014) and resilience (Thorne et al., 2002). Some authors argue that CAM worldviews and etiologies provide possible avenues of interpretation, which may play an influential role in the utilization of CAM (Cartwright \& Torr, 2005; McClean \& Shaw, 2005; Siahpush, 1999; Stratton \& McGivern-Snofsky, 2008).

CAM use has been predicted using Health Locus of Control (HLOC) as well, where most studies suggest Western CAM users are more likely to have an internal HLOC (Sasagawa, Martzen, Kelleher, \& Wenner, 2008; Schützler \& Witt, 2014). Furthermore, CAM use has been shown to positively correlate with constructs such as positive thinking (Arthur et al., 2012), optimism (Arthur et al., 2012; Buettner et al., 2006; Myers et al., 2008; Scheier \& Carver, 1985; van Tonder, Herselman, \& Visser, 2009), selfefficacy and agency (Arthur et al., 2012; Thompson, 2003; Thorne et al., 2002), as well as holistic thinking (Arthur et al., 2012; Barrett et al., 2003; Bishop et al., 2007; Maskarinec, Gotay, Tatsumura, Shumay, \& Kakai, 2001; Thorne et al., 2002). Yet such constructs differ in how they are defined and measured, suggesting that studies' use of identical construct labels does not necessarily imply that they are measuring the same phenomenon (Peters \& Crutzen, 2017; West et al., 2019).

There is an increasing number of studies exploring Modern Health Worries (MHW) (Petrie et al., 2001), beliefs concerning the perceived detrimental effects on health posed by modern, technological advances and devices. The MHW scale is comprised of four subscales: toxic interventions (TI), environmental pollution (EP), tainted food (TF), and radiation (RA). Items within the scale explore a wide 
range of attitudes that have been found to positively correlate with CAM use (Furnham, 2007). This wide range has the potential to provide useful leverage points for health promotion interventions aiming to decrease dysfunctional CAM reliance. However, these items are customarily aggregated, which precludes identification of viable intervention targets.

Concepts of health and illness comprise one system with other, non-healthcare concepts and concepts in the social network of the patient (Furnham, 1994). This conceptual framework and related attitudes are significant, as they influence the interpretation of symptoms, health and illness behavior, self-care, help-seeking, trusted sources of information, compliance, and coping (Fitzpatrick, 1989; Furnham, 1994; Good \& Delvecchio Good, 1980; Helman, 1994; JM Robbins \& Kirmayer, 1991). Beliefs underlying behavior are shaped by the individual's sociocultural environment and may vary in populations. Thus, behavioral determinants may differ to some degree for different behaviors and populations in various cultural contexts.

International studies have found that CAM users tend to retain a preference for the "natural", often defined as "clean", "healthy", and "not man-made" (Herzlich, 1995). What is "natural" is often linked to dietary considerations as well, such as consuming "organic" and "unprocessed" food that is not "genetically manipulated" and does not contain "toxins" or additives. Natural therapies are conceptualized as harmless and drawing on the body's "self-healing" mechanisms; these therapies are usually equated with herbal and folk or traditional medicine (Zörgő, Purebl, \& Zana, 2018). Pharmaceuticals are frequently seen as "chemicals" to be avoided if possible or at all costs (Connor, 2004; Furnham, 1994; D. Harris, 2000; McClean \& Shaw, 2005; Siahpush, 1999; Thorne et al., 2002).

Another prevalent attitude associated with CAM use in the West is psychosocial etiology manifesting in various concepts that elaborate a unidirectional causality between "soul" and body. Psychosocial phenomena are believed to cause somatic illnesses, and in turn, healing is also conceptualized as originating in psychological changes (Arnault, 2009; Garro, 2000; Kleinman, 1980; Ots, 1990; Siahpush, 
1999). Psychologization, as a "cultural mega-trend" in Western countries (Good \& Delvecchio Good, 1980; Mikaelsson, 2013) is regularly associated with CAM use, not just with regard to psychosocial etiology, but also because CAM users may conceptualize health as the transformation of the Self through illness (Frank, 1993; Thompson, 2003; Thorne et al., 2002), for which many CAM modalities offer frames of reference. Pharmaceuticals and biomedical procedures may be seen by the CAM user as inadequate treatment for somatic ailments that are "in reality" caused by psychosocial problems (Zörgő \& Olivas Hernández, 2018).

Vitalism - beliefs in concepts of energy - is also reported as a significant attitude amongst CAM users (Bishop et al., 2007; Goldstein, 2002; Zörgő \& Olivas Hernández, 2018) and may often constitute part of the "spirituality" dimension in quantitative surveys (Astin, 1998; Stratton \& McGivern-Snofsky, 2008; Thomson, Jones, Browne, \& Leslie, 2014). A belief in "universal energy" that courses through or gives rise to all living things may be accompanied by New Age concepts of man. In these interpretations, each individual is comprised of an idealized "Self" (sacred, eternal) and an "Ego" (profane, temporary); one must "learn" - via hardships like somatic illness - to identify more with the former and minimize the latter through the process of "personal growth" (Reddy, 2002). Vitalism may also include beliefs in elements of Eastern religions and philosophies, such as karma and reincarnation. Furthermore, these beliefs may be linked to teleological reasoning and illness or body symbolism (such as considering a hearing problem routed in a reluctance to "hear" something undesirable). The association between CAM use and attitudes related to vitalism has been documented in qualitative studies in various countries, such as the United States (Thompson, 2003), Australia (Coulter \& Willis, 2004), Denmark (Frisk, 2001), the United Kingdom (Heelas, 2013), Slovenia (Lüse \& Lázár, 2007), and Hungary (Zörgő, 2017).

Thus, many potential reasons for relying on CAM in addition to or instead of biomedicine have been identified, and while these reasons exhibit some similarities across populations, they also differ in some respects. Given that identification of attitudinal targets is a prerequisite of successfully discouraging 
dysfunctional CAM use, this is a lacuna that requires urgent resolution. Therefore, we compiled a large set of CAM-related attitudinal beliefs and report the analyses of modifiable determinants of CAM use at a sufficiently specific level to inform intervention development. Informing behavior change interventions that address dysfunctional CAM use requires mapping the beliefs held in the target population, in this case, Hungarian citizens.

In this study, we map the attitudinal beliefs in Hungary, based on the results from a qualitative study conducted between January 2015 and June 2017 (Zörgő et al., 2018). In that study, participant observation was carried out at four sites of Traditional Chinese Medicine (TCM) involving 105 patients, and semi-structured interviews were conducted with patients and practitioners of $\operatorname{TCM}(\mathrm{N}=20)$. We will explore the predominant attitudinal differences between participants in the biomedical group (BM) compared to the two CAM groups (CM and AM). We will also investigate whether these beliefs differ between $\mathrm{CM}$ and $\mathrm{AM}$ users and establish which beliefs predict dysfunctional CAM use most strongly, thereby identifying the promising targets for interventions aiming to decrease dysfunctional CAM use.

\section{Methods}

Sample size planning

Sample size planning was based on three considerations: power in a standard null hypothesis significance testing power analysis, sufficient accuracy when estimating parameters, and pragmatic considerations. CAM users are a hard-to-reach population, and therefore, the planned sample size had to remain realistic. In the ideal scenario, we would have recruited a sample size that would allow us to estimate the parameters of interest with sufficiently narrow confidence intervals (i.e. the accuracy in parameter estimation approach; Cumming, 2014; Maxwell, Kelley, \& Rausch, 2008). For Cohen's d, to obtain a $95 \%$ confidence interval with a maximum half-width of a tenth of a standard deviation requires between 1545 and 1660 participants (Peters \& Crutzen, 2019), which was not realistic. If we accepted a 
maximum half-width of one third of a standard deviation, between 142 and 146 participants are required, a more reasonable number. With 150 participants, equally distributed between the groups, one obtains $86 \%$ power against an effect size of half a standard deviation $(d=0.5)$. This seemed acceptable both from a research and practical perspective, so we aimed to recruit 165 participants, allowing for $10 \%$ of corrupt data (due to missing values or participants who did not participate seriously).

\section{Procedure}

The paper-based, self-administered survey was conducted in Budapest, Hungary between February 2017 and May 2017. One version was developed for CAM users and was administered at TCM clinics via the TCM practitioner. Patients were included who were 18 years of age and above, and had been a patient at the clinic for more than one month. Another version of the questionnaire was developed for individuals who do not employ CAM and was administered at general practitioner offices. The patients were approached by a researcher, were included if they were 18 years or above, and passed the following two filter questions: "Have you employed a CAM modality to treat an illness?" (must answer: no) and "Have you been treated by a biomedical doctor for an illness?" (must answer: yes). The two versions of the survey were identical regarding the attitude scale; the CAM questionnaire contained extra questions concerning CAM use. Participants in the study provided informed consent to participate anonymously. Approval was gained from the Semmelweis University Regional and Institutional Committee of Science and Research Ethics, reference number: SE TUKEB 6/2015.

\section{Analyses}

Diamond plots of the means were generated in order to compare participants who solely used biomedical treatment with those employing non-conventional medicine as either complementary or alternative treatment (Peters, 2017). To establish determinant relevance, we generated Confidence 
Interval-Based Estimation of Relevance (CIBER) plots (Crutzen, Peters, \& Noijen, 2017; Peters \& Crutzen, 2018). Diamond plots (of which CIBER plots are a specific implementation) were generated because they enable visualizing the raw data as well as the accuracy of estimates. Consistent with this line of reasoning, we will base our conclusions upon visual inspection of the results, rather than on applying "bright-line" rules, which are discouraged by the American Statistical Association (Wasserstein \& Lazar, 2016). All data, materials, and scripts are available at the Open Science Framework at https://osf.io/djkyf, enabling researchers to inspect the exact correlation coefficients and confidence intervals, conduct alternative analyses, or include the data in individual patient data meta-analyses.

\section{Results}

\section{Sample characteristics}

The sample comprised 151 participants after listwise deletion of missing values (157 before). There were more female participants than male (70\%). The proportion of survey participants who reported to prefer biomedicine were slightly higher (38\%) than the proportion who chose alternative or complimentary medicine ( $29 \%$ and $31 \%$ respectively). Those who chose biomedical services were on average younger $\left(\mathrm{M}_{\text {age }}=43\right.$ years old, $\left.95 \% \mathrm{Cl}=[38 ; 47]\right)$ compared to those in the other two groups ( $\mathrm{M}_{\text {age }}$ $=49$ in the $\mathrm{AM}$ group, $95 \% \mathrm{Cl}=[45 ; 53]$, and $\mathrm{M}_{\mathrm{age}}=50$ in the $\mathrm{CM}$ group, $\left.95 \% \mathrm{Cl}=[46 ; 55]\right)$. The proportion of females among those who reported to prefer $\mathrm{CM}$ and $\mathrm{BM}$ was slightly higher $(75 \%, 95 \% \mathrm{Cl}$ $=[60 \% ; 86 \%]$, and $71 \%, 95 \% \mathrm{Cl}=[57 \% ; 82 \%]$, respectively) compared to those who reported to prefer $\operatorname{AM}(67 \%, 95 \% \mathrm{Cl}=[51 \% ; 80 \%])$. The majority of people in every group identified themselves as Christians (36\% in the $\mathrm{AM}$ group, $95 \% \mathrm{Cl}=[22 \% ; 51 \%], 59 \% 95 \% \mathrm{Cl}=[43 \% ; 72 \%]$ in the $\mathrm{CM}$ group). It is worth noting that in the BM group, the second most frequently selected option of religious belonging was "not religious" $(29 \%, 95 \% \mathrm{Cl}=[18 \%$; $43 \%])$ whereas in the $\mathrm{AM}$ and the $\mathrm{CM}$ groups it was "religious in my own way" $(31 \%, 95 \% \mathrm{Cl}=[18 \% ; 47 \%]$, and $27 \%, 95 \% \mathrm{Cl}=[15 \% ; 42 \%]$, respectively, and $9 \%, 95 \% \mathrm{Cl}=$ 
[3\%; 19\%], in the BM group). In all three groups, the most frequently reported educational status was master's degree $(60 \%, 95 \% \mathrm{Cl}=[47 \% ; 73 \%]$, in the $\mathrm{BM}, 78 \%, 95 \% \mathrm{Cl}=[63 \% ; 89 \%]$, in the $\mathrm{AM}$ group, and $77 \%, 95 \% \mathrm{Cl}=[63 \% ; 88 \%]$, in the $\mathrm{CM}$ group) .

\section{Beliefs held by the three groups of participants}

Figure 1 shows the beliefs held in this sample. Points represent individual participant scores and diamonds represent the $95 \%$ confidence intervals for the means. Results are shown separately for the three groups of participants to facilitate comparison. Many beliefs were held similarly in all three groups, with no or trivial differences. Beliefs in which groups most overlapped included the determining role of the immune system, a healthy diet, and the low involvement of the social environment in the process of falling ill and healing. Also, all three groups agreed that one must suffer to attain health, and that chance and luck have little to do with falling ill or getting better.

However, many beliefs also differed, mostly exhibiting a pattern where the BM group stood in contrast to the other two groups. This was the case for beliefs related to various medicines and cures: the trustworthiness of traditional and ancient remedies compared to Western medicine; whether Western medicine only treats symptoms; whether pharmaceuticals are best avoided; whether serious symptoms call for visiting Western doctors; a preference for natural treatments; and the conviction that increased complaints indicate treatment effectiveness. Furthermore, the BM group differed in the level of importance assigned to emotions in falling ill. This was the case for beliefs such as that an imbalance between body and soul causes illness; that healing is solely determined by a patient's emotional development; that the symptomatic body part is indicative of an underlying psychosocial affliction which is interpreted symbolically; and that unprocessed trauma causes disease. Compared to the BM group, the $\mathrm{CM}$ and $\mathrm{AM}$ groups held stronger convictions in the validity of beliefs such as one attracts people and events that facilitate growth; one's body remembers everything (e.g. emotions, life events); 
reincarnation is real; in life, everything is connected to everything; nothing in life happens by chance; a concept of energy is shared by all Eastern religions and medicines; and illness aims to teach the patient something.

In most of these cases, the mean of the CM group was in between the means of the two other groups. However, the confidence intervals show that formal tests would not suggest that the $\mathrm{CM}$ group differed from the AM group. Nonetheless, the high consistency of these patterns suggests that participants in the $\mathrm{CM}$ group share characteristics with both of the other groups.

[Insert Figure 1 here]

Confidence Interval-Based Estimation of Relevance of potential intervention targets

The association patterns exhibited in Figure 1 are simultaneously consistent with the CM and AM groups being distinct groups in the population and with the $\mathrm{CM}$ and $\mathrm{AM}$ groups being indistinguishable. Therefore, we produced two CIBER plots. Figure 2 shows the differences in beliefs held by participants who did not use any non-conventional medicine and participants who used non-conventional medicine in some form (CM and $\mathrm{AM})$. Figure 3 shows the differences in beliefs held by participants who engaged in complementary use of non-conventional medicine and participants who engaged in alternative use of non-conventional medicine. The first CIBER plot is useful when developing interventions to discourage CAM use in general. However, if in reality $\mathrm{CM}$ users do differ from AM users, the primary intervention targets should be the beliefs distinguishing those two groups, as shown in the second CIBER plot. In the latter scenario, discouraging CAM use in general may backfire, since that also includes harmless CAM use (i.e. not dysfunctional CAM use), and may contribute to the stigmatization and alienation of the target population. Note that in these CIBER plots, all confidence intervals have been set to 95\%.

The patterns in Figure 2 suggest that, if need be, the CAM groups together are most effectively targeted with interventions addressing the beliefs that the body is interlaced with an energy system and that reincarnation is real. Similarly, significant beliefs include a distrust in biomedicine and not turning to 
a physician concerning a serious symptom. Additionally, important beliefs may include that natural and ancient remedies are more trustworthy than Western medicine, and that intensifying symptoms indicate treatment efficacy. Other, slightly less relevant beliefs are the influential role of emotions in healing, and the conviction that illness occurs in order to teach an individual something. Figure 3 shows the CIBER plot comparing participants in the $\mathrm{CM}$ group versus those in the $\mathrm{AM}$ group. These patterns suggest that in interventions for CAM users most at risk from dysfunctional CAM use (those in the AM group), it is important to target the belief that natural treatments should always be preferred. Furthermore, the AM group left less interpretive space for a genetic etiology and exhibited a decreased need for verifying their illness or healing with biomedical test results; thus, these beliefs seem to be important intervention targets as well. Finally, the AM group was less likely to turn to a biomedical doctor with a serious symptom, which, although is likely measured behavior rather than attitude, does capture dysfunctional CAM use accurately.

[Insert Figure 2 here], [Insert Figure 3 here]

\section{Discussion}

\section{Recommendations for intervention development}

Our objective was to map attitudinal differences between patients using solely biomedicine and those using non-conventional medicine. We also explored whether any attitudinal differences can be pinpointed between the $\mathrm{CM}$ and $\mathrm{AM}$ groups, thus lending insight into the beliefs most responsible for dysfunctional CAM use and signify promising intervention targets. In order to achieve the latter, we generated CIBER plots to establish determinant relevance.

Comparative diamond plots of the means revealed that although there were beliefs shared by the entire sample, there was a marked difference between the BM and CAM groups. These differences were beliefs concerning various medical systems; the level of importance assigned to emotions in falling ill and healing; and vitalism or Eastern concepts. 
The CIBER plots for BM versus CAM revealed that the most successful intervention targets seem to be regarding beliefs in vitalism on the one hand, and distrust in biomedicine on the other. If $\mathrm{CM}$ and $\mathrm{AM}$ groups are taken as separate intervention targets, as would be indicated for addressing dysfunctional CAM use, then the most promising beliefs appear to be not preferring a natural cure and relying more on biomedical testing, which would in turn, possibly affect trusting a physician with a serious symptom. Targeting the need for biomedical testing would be essential for patients in receiving adequate care for their ailment in time, as dysfunctional CAM use may be coupled with healthcare avoidance or a delay in presentation (Akram, Siddiqui, \& Karimi, 2014; Byrne, 2008; George \& Topaz, 2013; Khakbazan, Taghipour, Latifnejad, \& Mohammadi, 2014).

The similarity between $\mathrm{CM}$ and $\mathrm{AM}$ beliefs may denote that there is no major difference between the two types of non-conventional medicine users. However, the consistency in the patterns of the three means, where the CM group mean almost always fell in between the other two group means, suggests that those using both biomedicine and non-conventional medicine may share beliefs with both other groups. Future research with larger sample sizes will yield more accurate estimates (as manifest in more tight confidence intervals) and will allow determining whether these patterns represent sampling and measurement error or patterns present in the population.

It is vital to note that belonging to these groups is not static - every symptom, illness or change in condition may induce a new therapy choice on the part of the patient. Dysfunctional CAM use can only occur among patients who use non-conventional treatments as an alternative to biomedicine concerning a condition that is life-threatening. Thus, alternative CAM use is not always dysfunctional: for example, a patient may use homeopathy or herbs to treat a common cold. It is also important to note that attitudes and intentions do not perfectly predict behavior (Fishbein \& Ajzen, 2010; Godin \& Kok, 1996), for example, a patient may exhibit a strong conviction to avoid pharmaceuticals, yet because of their condition, may be forced to regularly take them. 


\section{Fit with existing findings and theory}

All groups in our sample believed that chance and luck have little to do with falling ill and healing, which may suggest that attributing meaning is important to all participants regardless of therapy choice. This may also suggest that, contrary to some studies' findings (Kleinman, 1995; Knoll, 2004), biomedicine does in fact provide an adequate interpretive framework to patients concerning their ailment, albeit not for every individual, due to personal preferences and circumstances.

The attitudes in which the BM group in our study exhibited the most differences compared to the $\mathrm{CM}$ and $\mathrm{AM}$ groups involved trust toward various medical systems. As expounded in previous studies involving so called "push factors" in CAM use (Vincent \& Furnham, 1996), CAM users may exhibit a decreased trust in biomedicine. This loss of trust can be observed in attitudes within our study where CAM users were more likely to trust "ancient" and "traditional" remedies and were less likely to turn to a physician with a symptom deemed serious.

Two pivotal points where the biomedical and CAM groups differed was the latter's preference for "natural" cures and the avoidance of pharmaceuticals. These two attitudes are often co-present in individuals; a prevalent etiology among CAM users is illness caused by the accumulation of "toxins" (food additives, "chemicals", etc.) in the body, which is conceptualized as an inevitable part of modern, urbanized life (Furnham, 1994). A congruent practice is "detoxification" via various diets and cleansing processes to regain health. CAM use may be associated with a "clean" and "natural" way of achieving health, while also resisting modern dangers (Connor, 2004). In such a worldview, pharmaceuticals are frequently perceived as toxic chemicals (Reich, 2016; Siahpush, 1999). Siahpush argues that these attitudes may have a metaphoric element as well: if the body is seen as "part of nature", it can be "polluted" similarly to environmental pollution (Siahpush, 1999). The idea of pollution is central to Modern Health Worries as well, which have previously been linked to CAM use (Furnham, 2007). 
Another set of attitudes where biomedicine and CAM groups differed greatly concern the role of psychosocial factors in illness and healing. CAM groups credited emotions with a crucial role in causing illness, namely, through the imbalance of body and soul, or trauma that goes unprocessed by the individual. Several studies have found that psychosocial etiology predicts CAM use (Bishop et al., 2007; Köteles, 2014; Maskarinec et al., 2001). Other scholars have argued that interpreting somatic illness in a psychosocial frame is characteristic of many cultures and posited that separating the biological domain from emotional and social aspects of the illness experience was only made possible with the relatively recent emergence of biomedicine, biotechnology, and modern diagnostics (Arnault, 2009; Garro, 2000; Kleinman, 1980; Ots, 1990). Tangentially, our results also show that the CAM groups gave credence to the role of "emotional development" or "personal growth" in healing, which may correspond to the conviction that illness is trying to teach the patient how to grow; thus, somatic ailments receive a symbolic interpretation (e.g.: a throat infection means one is reluctant to "say" something). According to many authors, the rise of popular psychology and therapy-culture (Mikaelsson, 2013) in the West has led to an increasing psychologization (Good \& Delvecchio Good, 1980; Thorne et al., 2002) in the interpretation of somatic disease. In the present study, this may relate to the conviction among CAM users that biomedicine only treats the symptoms of an illness; if a psychosocial interpretation of a somatic ailment is seen as a causative factor, then the biomedical cure may be perceived as mere symptomatic treatment.

A strong conviction in psychosocial etiology may also result in a decreased reliance on biomedical test results when monitoring one's condition. Due to the belief that physical illness is caused by an underlying emotional problem, test results may either not be important to the patient or the individual may be convinced that psychosocial growth will eventually be manifested in physical healing as well. Needing to see one's illness or remission verified in biomedical testing was equally important for 
the $\mathrm{BM}$ and $\mathrm{CM}$ group, but the CIBER plot results show that this attitude connotes a significant difference between the $\mathrm{CM}$ and $\mathrm{AM}$ group.

The last analytical domain where the biomedical and CAM groups differed in terms of attitude can be interpreted along the lines of vitalism and teleology. Vitalism entails a belief in concepts of "universal energy"; this energy courses through the human body and, more broadly, gives rise to all things within the universe. Such a "vital force" is often linked to concepts of energy in various medical systems (e.g.: "qi" in Traditional Chinese Medicine, "prana" in Ayurvedic or Tibetan medicine); this energy is then assumed to connect all living things and enable reincarnation as well. Teleological reasoning, that is, explaining events by assigning a grander purpose to them (Kelemen, 1999) can be associated with attitudes that exclude chance in life events, viewing illness as having a didactic quality, and the idea that one attracts people and events that serve some kind of greater purpose of growth. All of these attitudes were more espoused by the CAM groups in our study, compared to the biomedical group. The emphatic presence of vitalism and teleology in the worldview of CAM users is in accordance with previous findings (Bishop et al., 2007; Goldstein, 2002).

The preference for natural treatments, beliefs in psychosocial etiology and vitalism coincide with values of a subculture Ray and Anderson called "cultural creatives", claiming $24 \%$ of the American population can be characterized as belonging to this group (Ray \& Anderson, 2001); Stratton estimated a further 80-90 million cultural creatives in Europe (Stratton \& McGivern-Snofsky, 2008). Cultural creatives share values such as ecological sustainability, a preference for the exotic and foreign, social optimism, spirituality, and mind-body unity (Astin, 1998; Ray \& Anderson, 2001; Stratton \& McGivern-Snofsky, 2008). According to Stratton, adherents exhibiting any constellation of said attitudes, represent "the core market" for CAM (Stratton \& McGivern-Snofsky, 2008). Our results reflect these values, as CAM users had a more marked preference for concepts linked to Eastern philosophy, religion, and medicine, while the "religious in my own way" category in our sample (31\% in the alternative group, $27 \%$ in the 
complementary, and significantly lower in the biomedicine group at 9\%) may be interpreted as "spirituality".

\section{Limitations and strengths}

Our study had several limitations. Firstly, the hard-to-reach nature of the target population means that although we achieved our sample size planning goals, we had to adjust those to what seemed feasible a priori. Had we been able to recruit more participants, we would have had more certainty as to whether the $\mathrm{CM}$ and $\mathrm{AM}$ groups are ultimately different or hardly distinguishable. In future research, it may be necessary (and in any case, beneficial) to collect data in multiple locales (perhaps countries).

Secondly, our research was based in the urban capital of Hungary. This may threaten generalizability of the findings, as some studies have concluded that CAM use motivations may differ between urban and rural settings, not only because of differences in education levels, but also in access to conventional healthcare, and differing CAM-related beliefs (Buda, 2004; Stratton \& McGivern-Snofsky, 2008; Szántó, 2005). Future research, therefore, should try to recruit participants from both urban and rural settings.

Thirdly, strategies for dealing with illness, thus choice of therapy, are not only contingent on attitudes, but on clinical factors as well. These clinical factors may change over time, influencing employed therapies also. Furthermore, exhibited behavior may differ from illness to illness; consequently, group belonging of patients is not static. Moreover, although there is evidence that the examined attitudes are shared among CAM users in Western countries (Eardley et al., 2012), the level of transferability of our results is unclear. Lastly, due to the fact that CAM patients were recruited in clinics of Traditional Chinese Medicine by their practitioners, there may have been a potential selection bias. 
This study also had a number of strengths. Firstly, CAM users are regularly examined as a unified group and set in contrast to users of solely conventional medicine, without separating patterns of use into complementary and alternative forms. Treating CAM patients as a homogeneous group leads to oversimplification: for example, not all CAM use has detrimental effects on conventional therapy; not all CAM use is medically unwarranted, as in the case of many chronic diseases; and there are instances when non-conventional medicine is the only feasible alternative because biomedicine does not offer a cure. In order to avoid oversimplification and to bolster intervention effectiveness by allowing personalization, we have introduced the distinction of "dysfunctional CAM use". Secondly, although there are studies scrutinizing motivations for CAM use, there are few analyzing specific attitudes involved. CAM use is frequently examined relative to psychological constructs with identical label names not denoting the same phenomenon (e.g.: positive thinking, holism, spirituality). This is particularly problematic because, albeit interesting from a theoretical perspective, results from such studies leave intervention developers seeking to discourage dysfunctional use of non-conventional medicine emptyhanded, as no behavior change principles have (as yet) been identified that successfully target positive thinking or holism (Kok et al., 2016). This study did address specific attitudinal beliefs as collected in earlier qualitative research, and produced CIBER plots that can guide intervention development.

\section{Conclusions}

Albeit much research has been carried out on the motivations behind CAM use, rarely do studies treat complementary and alternative CAM users separately in order to scrutinize patterns of nonconventional medicine use and underlying cognition. Furthermore, insufficient attention is given to a subset of alternative CAM users, patients employing non-conventional therapies for a life-threatening condition. This study has made preliminary steps in pinpointing attitudes that may signify or predict dysfunctional CAM use so as to inform future intervention development. Such interventions would be 
essential for the prevention of incidents and mortality. Further research is needed to confirm our results and to continue mapping attitudes specifically focused on a population of dysfunctional CAM users.

\section{Acknowledgments}

The authors would like to thank all participating general practitioners, Traditional Chinese Medicine practitioners, and patients. Furthermore, the authors would like to acknowledge the support of ÚNKP18-3-III New National Excellence Program of the Ministry of Human Capacities. Thank you to Ferenc Köteles and Zsuzsa Győrffy for their insights on the questionnaire design.

Adler, S., \& Fosket, J. (1999). Disclosing complementary and alternative medicine use in the medical encounter: a qualitative study in women with breast cancer. J Fam Pract., 48(6), 453-458.

Akram, M., Siddiqui, S., \& Karimi, A. (2014). Patient Related Factors Associated with Delayed Reporting in Oral Cavity and Oropharyngeal Cancer. Int J Prev Med., 5(7), 915-919.

Arnault, D. (2009). Cultural Determinants of Help Seeking: A model for research and practice. Res Theory Nurs Pract., 23(4), 259-278.

Arthur, K., Belliard, J., Hardin, S., Knecht, K., Chen, C., \& Montgomery, S. (2012). Practices, Attitudes, and Beliefs associated with Complementary and Alternative Medicine (CAM) use among Cancer Patients. Integr Cancer Ther., 11(3), 232-242.

Astin, J. (1998). Why patients use alternative medicine: results of a national study. JAMA, 279, 1548-53. Bahall, M. (2015). Complementary and alternative medicine usage among cardiac patients: a descriptive study. BMC Complement Altern Med., 15(100). 
Bann, C., Sirois, F., \& Walsh, E. (2010). Provider Support in Complementary and Alternative Medicine: Exploring the Role of Patient Empowerment. Journal of Alternative and Complementary Medicine, 16(7), 745-752.

Barrett, B., Marchand, L., Scheder, J., Plane, M., Maberry, R., Appelbaum, D., ... Rabago, D. (2003). Themes of holism, empowerment, access, and legitimacy define complementary, alternative, and integrative medicine in relation to conventional biomedicine. J Altern Complement Med., 9(6), 937-947.

Bartholomew Eldredge, L. K., Markham, C. M., Ruiter, R. A. C., Fernàndez, M. E., Kok, G., \& Parcel, G. S. (2016). Planning health promotion programs: An Intervention Mapping approach. San Francisco: Jossey-Bass.

Bishop, F., Yardley, L., \& Lewith, G. (2007). A systematic review of beliefs involved in the use of complementary and alternative medicine. J Health Psychol., 12(6), 851-867.

Buda, L. (2004). Az alternatív medicina tudományos orvosláshoz való viszonyának, társadalmi-lélektani, egészség-szociológiai hátterének elemzése és az egészségügyi ellátásban betöltött szerepének komplex empirikus vizsgálata. Pécsi Tudományegyetem, Általános Orvostudományi Kar, Pécs. Buettner, C., Kroenke, C., Phillips, R., Davis, R., Eisenberg, D., \& Holmes, M. (2006). Correlates of use of different types of complementary and alternative medicine by breast cancer survivors in the nurses' health study. Breast Cancer Research and Treatment., 100(2), 219-227.

Byrne, S. (2008). Healthcare Avoidance: A Critical Review. Holistic Nursing Practice, 22(5), 280-292.

Cartwright, T., \& Torr, R. (2005). Making sense of illness: the experiences of users of complementary medicine. J Health Psychol., 10(4), 559-572.

Connor, L. (2004). Relief, risk and renewal: mixed therapy regimens in an Australian suburb. Soc Sci Med., 59(8), 1695-705. 
Coulter, I., \& Willis, E. (2004). The rise and rise of complementary and alternative medicine: a sociological perspective. Med J Aust., 180(11), 587-589.

Crocetti, E., Crotti, N., Feltrin, A., Ponton, P., Geddes, M., \& Buiatti, E. (1998). The use of complementary therapies by breast cancer patients attending conventional treatment. European Journal of Cancer, 34(3), 324-328.

Crutzen, R., \& Peters, G.-J. Y. (2018). Evolutionary learning processes as the foundation for behaviour change. Health Psychology Review, 12(1), 43-57.

Crutzen, R., Peters, G.-J. Y., \& Noijen, J. (2017). Using Confidence Interval-Based Estimation of Relevance to select social-cognitive determinants for behaviour change interventions. Frontiers in Public Health, 5, 165.

Csordas, T. (1997). The sacred self: a cultural phenomenology of charismatic healing. Berkeley: University of California Press.

Cumming, G. (2014). The New Statistics: Why and How. Psychological Science, 25(1), 7-29.

Davis, E., Oh, B., Butow, P., Mullan, B., \& Clarke, S. (2012). Cancer patient disclosure and patient-doctor communication of complementary and alternative medicine use: a systematic review. Oncologist, 17(11), 1475-1481.

Deng, G. (2008). Integrative cancer care in a US academic cancer centre: the Memorial Sloan-Kettering experience. Current Oncology., 15(2), S68-S71.

Eardley, S., Bishop, F., Prescott, P., Cardini, F., Brinkhaus, B., Santos-Rey, K., ... Lewith, G. (2012). A systematic literature review of complementary and alternative medicine prevalence in EU. Forsch Komplementmed., 19(Supp/ 2), 18-28.

Eisenberg, D., Davis, R., Ettner, S., Appel, S., Wilkey, S., Van Rompay, M., \& Kessler, R. (1998). Trends in Alternative Medicine Use in the United States, 1990-1997. JAMA, 280(18), 1569-1575. 
Eliason, B., Huebner, J., \& Marchand, L. (1999). What physicians can learn from consumers of dietary supplements. Journal of Family Practice., 48(6), 459-463.

Ernst, E. (2000). Prevalence of use of complementary/alternative medicine: a systematic review. Bulletin of the World Health Organization, 78(2).

Faith, J., Thorburn, S., \& Tippens, K. (2013). Examining CAM use disclosure using the behavioral model of health services use. Complement Ther Med., 21(5), 501-508.

Farrukh, M., Makmor-Bakry, M., Hatah, E., \& Tan, H. (2018). Use of complementary and alternative medicine and adherence to antiepileptic drug therapy among epilepsy patients: a systematic review. 12, 2111-2121.

Fishbein, M., \& Ajzen, I. (2010). Predicting and Changing Behavior: The Reasoned Action Approach. New York: Taylor \& Francis Group.

Fitzpatrick, R. (1989). Lay concepts of illness. In Perspectives in Medical Sociology. (Brown, P (ed.), pp. 254-267). Prospect Heights, IL: Waveland Press.

Frank, A. (1993). The Rhetoric of Self-Change: Illness Experience as Narrative. The Sociological Quarterly, 34(1), 39-52.

Frass, M., Strassl, R., Friehs, H., Müllner, M., Kundi, M., \& Kaye, A. (2012). Use and acceptance of complementary and alternative medicine among the general population and medical personnel: a systematic review. Ochsner J., 12(1), 45-56.

Frisk, L. (2001). Globalization or Westernization? New Age as a Contemporary Transnational Culture. In New age religion and globalization. (Rothstein M (ed.), pp. 31-41). Aarhus: Aarhus University Press.

Furnham, A. (1994). Explaining health and illness: lay perceptions on current and future health, the causes of illness, and the nature of recovery. Soc Sci Med., 39(5), 715-725. 
Furnham, A. (2007). Are modern health worries, personality and attitudes to science associated with the use of complementary and alternative medicine? Br J Health Psychol, 12, 229-243.

Garro, L. (1998). On the rationality of decision-making studies: Part 1: Decision models of treatment choice. Med Anthropol Q., 12(3), 319-340.

Garro, L. (2000). Cultural meaning, explanations of illness, and the development of comparative frameworks. Ethnology, 39(4), 305-33.

George, M., \& Topaz, M. (2013). A systematic review of complementary and alternative medicine for asthma self-management. The Nursing Clinics of North America, 48(1), 53-149.

Godin, G., \& Kok, G. (1996). The theory of planned behavior: A review of its applications to health-related behaviors. American Journal of Health Promotion, 11(2), 87-98.

Goldstein, M. (2002). The Emerging Socioeconomic and Political Support for Alternative Medicine in the United States. Annals of the American Academy of Political and Social Science, 583(1).

Good, B., \& Delvecchio Good, M. (1980). The meaning of symptoms: a cultural hermeneutic model for clinical practice. In The Relevance of Social Science for Medicine (L. Eisenberg, A. Kleinman (eds.), pp. 165-196). Boston: D. Reidel Publishing Company.

Harris, D. (2000). The Natural. Salmagundi, 126(127), 236-251.

Harris, P. (2012). Prevalence of complementary and alternative medicine (CAM) use by the general population: a systematic review and update. Int J Clin Pract., 66(10), 924-939.

Heelas, P. (2013). On transgressing the secular: spiritualities of life, idealism, vitalism. In New age spirituality: rethinking religion. (SJ Sutcliffe, IS Gilhus (eds.), pp. 66-83). Durham, England: Acumen Publishing.

Helman, C. (1994). Culture, health and illness. Oxford: Butterworth-Heinemann. Herzlich, C. (1995). Modern medicine and the quest for meaning. Illness as a social signifier. In The meaning of illness. (Augé M, Herzlich C (eds.), pp. 151-173). Harwood Academic Publishers. 
Huiart, L., Bouhnik, A., Rey, D., Rousseau, F., \& Retornaz, F. (2013). Complementary or Alternative Medicine as Possible Determinant of Decreased Persistence to Aromatase Inhibitor Therapy among Older Women with Non-Metastatic Breast Cancer. PLOS ONE, 8(12), e81677.

Hunt, K., Coelho, H., Wider, B., Perry, R., Hung, S., Terry, R., \& Ernst, E. (2010). Complementary and alternative medicine use in England: results from a national survey. Int J Clin Pract., 64(11), 1496-1502.

Kaptchuk, T., Edwards, R., \& Eisenberg, D. (1996). Complementary medicine-efficacy beyond the placebo effect. In Complementary medicine: an objective appraisal. (Ernst, E (ed.), pp. 42-70). Oxford, England: Butterworth Heinemann.

Kelemen, D. (1999). Why are Rocks pointy? Children's preference for teleological explanations of the natural world. Developmental Psychology, 35(6), 1440-1452.

Kelner, M., \& Wellman, B. (1997). Health care and consumer choice: medical and alternative therapies. Soc Sci Med., 45, 203-212.

Khakbazan, Z., Taghipour, A., Latifnejad, R., \& Mohammadi, E. (2014). Help Seeking Behavior of Women with Self-Discovered Breast Cancer Symptoms: A Meta-Ethnographic Synthesis of Patient Delay. PLOS ONE, 9(12), e110262.

Kleinman, A. (1980). Patients and healers in the context of culture. Berkeley: University of California Press.

Kleinman, A. (1995). What is Specific to Biomedicine? In Writing at the Margin: Discourse between Anthropology and Medicine. (pp. 21-40). Berkeley: University of California Press.

Knoll, A. (2004). The reawakening of complementary and alternative medicine at the turn of the twentyfirst century: filling the void in conventional biomedicine. J Contemp Health Law Policy, 20(2), 329-66. 
Kok, G., Gottlieb, N. H., Peters, G.-J. Y., Mullen, P. D., Parcel, G. S., Ruiter, R. A. C., ... Bartholomew, L. K. (2016). A taxonomy of behavior change methods: an Intervention Mapping approach. Health Psychology Review, 10(3), 297-312.

Köteles, F. (2014). A Holisztikus Természetgyógyászat Kérdőív magyar változatának (HCAMQ-H) pszichometriai vizsgálata. Mentálhigiéné És Pszichoszomatika, 15(1), 49-65.

Lövgren, M., Wilde-Larsson, B., Hök, J., Leveälahti, H., \& Tishelman, C. (2011). Push or pull? Relationships between lung cancer patients' perceptions of quality of care and use of complementary and alternative medicine. Eur J Oncol Nurs., 15(4), 311-7.

Lüse, A., \& Lázár, I. (2007). Introduction. In Cosmologies of suffering: post-communist transformation, sacral communication, and healing. (Lüse, A and Lázár I (eds.)). Newcastle, UK: Cambridge scholars publishing.

Maskarinec, G., Gotay, C., Tatsumura, Y., Shumay, D., \& Kakai, H. (2001). Perceived cancer causes: use of complementary and alternative therapy. Cancer Pract., 9(4), 183-190.

Maxwell, S. E., Kelley, K., \& Rausch, J. R. (2008). Sample size planning for statistical power and accuracy in parameter estimation. Annual Review of Psychology, 59, 537-63.

McClean, S., \& Shaw, A. (2005). From Schism to Continuum? The Problematic Relationship Between Expert and Lay Knowledge - An Exploratory Conceptual Synthesis of Two Qualitative Studies. Qualitative Health Research, 15(6), 729-749.

Mikaelsson, L. (2013). New Age and the spirit of capitalism: energy as cognitive currency. In New age spirituality: rethinking religion (Sutcliffe SJ, Gilhus IS (eds.), pp. 160-173). Acumen Publishing. Myers, C., Jacobsen, P., Huang, Y., Frost, M., Patten, C., Cerhan, J., \& Sellers, T. (2008). Familial and perceived risk of breast cancer in relation to use of complementary medicine. Cancer Epidemiology Biomarkers \& Prevention, 17(6), 1527-1534. 
O'Callaghan, F., \& Jordan, N. (2003). Postmodern values, attitudes and the use of complementary medicine. Complementary Therapies in Medicine, 11, 28-32.

Ots, T. (1990). The angry liver, the anxious heart and the melancholy spleen. The Phenomenology of Perceptions in Chinese Culture. Culture, Medicine and Psychiatry, 14, 21-58.

Pawluch, D., Cain, R., \& Gillett, J. (2000). Lay constructions of HIV and complementary therapy use. Soc Sci Med., 51, 251-64.

Peters, G.-J. Y. (2014). A practical guide to effective behavior change: How to identify what to change in the first place. European Health Psychologist, 16(5), 142-155.

Peters, G.-J. Y., \& Crutzen, R. (2017). Pragmatic nihilism: how a Theory of Nothing can help health psychology progress. Health Psychology Review, 11(2).

Peters, G.-J. Y., \& Crutzen, R. (2018). Establishing determinant importance using CIBER: an introduction and tutorial. European Health Psychologist, 20(3), 485-495.

Peters, G.-J. Y., \& Crutzen, R. (2019). Knowing how effective an intervention, treatment, or manipulation is and increasing replication rates: accuracy in parameter estimation as a partial solution to the replication crisis. PsyArXiv. https://doi.org/10.31234/osf.io/cjsk2

Petrie, K., Sivertsen, B., Hysing, M., Broqadbent, E., Moss-Morris, R., Eriksen, H., \& Ursin, H. (2001). Thoroughly modern worries: The relationship of worries about modernity to reported symptoms, health and medical care utilisation. Journal of Psychosomatic Research, 51, 395-401.

Pierret, J. (2003). The illness experience: state of knowledge and perspectives for research. Sociology of Health \& IIIness, 25, 4-22.

Ray, P., \& Anderson, S. (2001). The Cultural Creatives: How 50 Million People are Changing the World. New York: Three Rivers Press.

Reddy, S. (2002). Asian Medicine in America: The Ayurvedic Case. Annals of the American Academy of Political and Social Science., 583, 97-121. 
Reich, J. (2016). Vaccines as Unnatural Intervention. In Calling the shots - why parents reject vaccines (pp. 97-117). New York, NY: New York University Press.

Robbins, J. (2004). The globalization of Pentecostal and Charismatic Christianity. Annual Review of Anthropology, 33, 117-143.

Robbins, JM, \& Kirmayer, L. (1991). Attributions of common somatic symptoms. Psychological Medicine, 21(4), 1029-1045.

Rossi, E., Bellandi, T., Picchi, M., Baccetti, S., Monechi, M., Vuono, C., \& Tartaglia, R. (2017). Patient Safety in Complementary Medicine through the Application of Clinical Risk Management in the Public Health System. Medicines, 4(4), 93.

Sasagawa, M., Martzen, M., Kelleher, W., \& Wenner, C. (2008). Positive correlation between the use of complementary and alternative medicine and internal health locus of control. Explore, 4(1), 3841.

Scheier, M., \& Carver, C. (1985). Optimism, coping, and health - assessment and implications of generalized outcome expectancies. Health Psychology., 4(3), 219-247.

Schützler, L., \& Witt, C. (2014). Internal health locus of control in users of complementary and alternative medicine: a cross-sectional survey. BMC Complement Altern Med., 14(320).

Seely, D., \& Oneschuk, D. (2008). Interactions of natural health products with biomedical cancer treatments. Current Oncology, 15(Suppl 2), s109.es81-s10.es6.

Siahpush, M. (1999). Postmodern attitudes about health: a population-based exploratory study. Complementary Therapies in Medicine, 7, 164-169.

Singh, H., Maskarinec, G., \& Shumay, D. (2005). Understanding the motivation for conventional and complementary/alternative medicine use among men with prostate cancer. Integrative Cancer. Therapies, 4(2), 187-194. 
Stevinson, C., \& Ernst, E. (2006). Why patients use complementary and alternative medicine. In The desktop guide to complementary and alternative medicine - an evidence-based approach. (Ernst E, Pittler MH, Wider B (eds.), pp. 501-10). London: Mosby Elsevier Ltd.

Stratton, T., \& McGivern-Snofsky, J. (2008). Toward a sociological understanding of complementary and alternative medicine use. J Altern Complement Med., 14(6), 777-783.

Szántó, Z. (2005). PhD értekezés. Az egészséggel kapcsolatos életstílus: betegviselkedés és égészségviselkedés. Semmelweis Egyetem, Magatartástudományi Intézet, Budapest.

Thomas, K., Nicholl, J., \& Coleman, P. (2001). Use and expenditure on complementary medicine in England: a population based survey. Complement Ther Med., 9, 2-11.

Thompson, C. (2003). Natural health discourses and the therapeutic production of consumer resistance. The Sociological Quarterly, 44(1), 81-107.

Thomson, P., Jones, J., Browne, M., \& Leslie, S. (2014). Psychosocial factors that predict why people use complementary and alternative medicine and continue with its use: A population based study. Complementary Therapies in Clinical Practice, 20(4), 302-310.

Thorne, S., Paterson, B., Russell, C., \& Schultz, A. (2002). Complementary/alternative medicine in chronic illness as informed self-care decision making. Int J Nurs Stud., 39, 671-83.

Tindle, H., Davis, R., Phillips, R., \& Eisenberg, D. (2005). Trends in use of complementary and alternative medicine by US adults: 1997-2002. Altern Ther Health Med., 11(1), 42-9.

van Tonder, E., Herselman, M., \& Visser, J. (2009). The prevalence of dietary-related complementary and alternative therapies and their perceived usefulness among cancer patients. Journal of Human Nutrition and Dietetics, 22(6), 528-535.

Vincent, C., \& Furnham, A. (1996). Why do patients turn to complementary medicine? An empirical study. Br J Clin Psychol., 35(1), 37-48. 
Vincent, C., \& Furnham, A. (1997). The perceived efficacy of complementary and orthodox medicine: a replication. Complement Ther Med, 5, 85-89.

Wasserstein, R. L., \& Lazar, N. A. (2016). The ASA's Statement on p-Values: Context, Process, and Purpose. The American Statistician, 70(2), 129-133.

West, R., Godinho, C. A., Bohlen, L. C., Carey, R. N., Hastings, J., Lefevre, C. E., \& Michie, S. (2019). Development of a formal system for representing behaviour-change theories. Nature Human Behaviour, 3(5), 526.

Wieland, L., Manheimer, E., \& Berman, B. (2011). Development and classification of an operational definition of complementary and alternative medicine for the Cochrane collaboration. Altern Ther Health Med, 17(2), 50-59.

Yarney, J., Donkor, A., Opoku, S., Yarney, L., Agyeman-Duah, I., Abakah, A., \& Asampong, E. (2013). Characteristics of users and implications for the use of complementary and alternative medicine in Ghanaian cancer patients undergoing radiotherapy and chemotherapy: a cross-sectional study. BMC Complement Altern Med., 13(1), 16.

Yates, J., Mustian, K., Morrow, G., Gillies, L., Padmanaban, D., Atkins, J., ... Colman, L. (2005). Prevalence of complementary and alternative medicine use in cancer patients during treatment. Support Care Cancer, 13(10), 806-811.

Zörgő, S. (2017). Pszichoszociális etiológia a hagyományos kínai orvoslást alkalmazók körében - A „lelki eredetü" testi betegség laikus oki teóriái. Kultúra És Közösség, 8(4), 107-119.

Zörgő, S., \& Olivas Hernández, O. (2018). Patient Journeys of Nonintegration in Hungary: A Qualitative Study of Possible Reasons for Considering Medical Modalities as Mutually Exclusive. Integrative Cancer Therapies, 17(4), 1270-1284.

Zörgő, S., Purebl, G., \& Zana, Á. (2018). A Qualitative Study of Culturally Embedded Factors in Complementary and Alternative Medicine Use. BMC Complementary and Alternative Medicine. 
The human body is interlaced with a (spiritual) energetic system (chi).

eve in reincarnation.

Ancient remedies are more trustworthy than western medicine.

I only look for natural treatments to

Every illess enters our life in order teach us something.

If my complaints intensify due to a effective and I will get better soon. Healing always begins with confronting. an emotional problem.

Western medicine only treats symptoms. With a serious symptom I always turn to

I consciously avoid pharmaceuticals.

I trust traditional remedies more than It is important which organ/body part gets sick because that tells us abo
the reason for falling ill. The belief in energy (chí, prana, etc.) is shared by all eastern religions and

Nothing in life happens by chance. Chemotherapy does more harm than good.

Our body remembers everything (emotions, lie events, elc.). My healing is solely the result of my

In life, everything is connected to Radiation therapy does more harm than If a trauma is left unprocessed,
will eventually cause an illness in the You attract people and events that help Our mind can have a strong effect on
our healing. Electronic devices emit radiation that

I trust western doctors. If I get well emotionally, then my symptoms/illness will disappear An imbalance between body and soul will Every illness is caused by emotional Health can be maintained with regular

If I get sick, it is mostly by chance. need to see my healing verified in a test result (blood test, ultrasounc.

You shouldn't perform a biopsy on a
tumor.

I do not agree with mandatory vaccines.

The body is a mirror to the soul.

|llness is always caused by genetic factors or inherited susceptibility. I expect my doctor/practitioner to heal

I try to keep a healthy diet.

My healing is mostly due to luck.

Every illness is caused by a weak.

Falling ill and healing are largely nvironment (family, friends, etc.).

You must suffer in order to get well

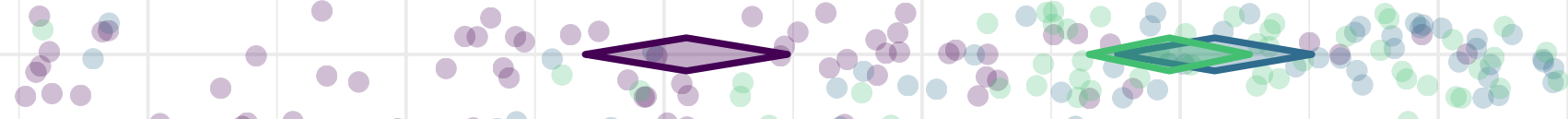

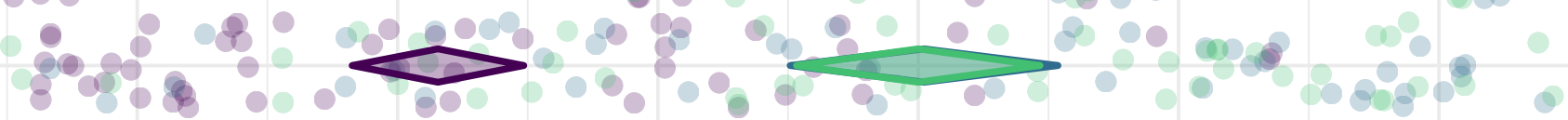

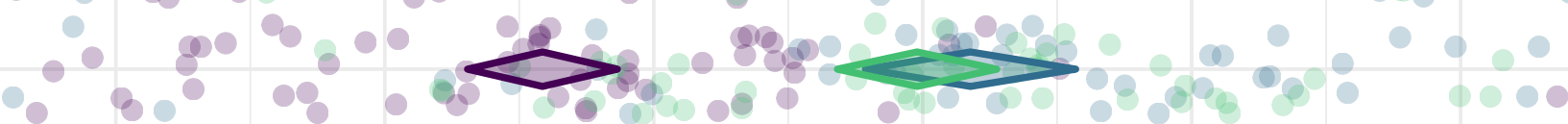

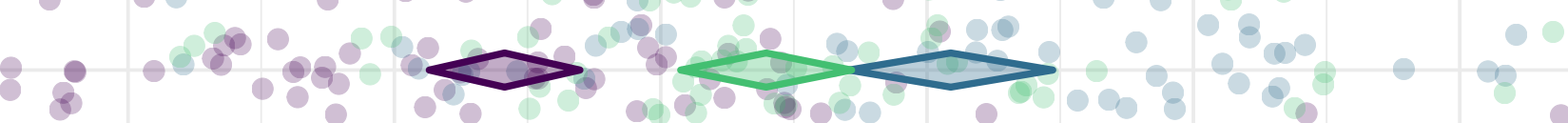

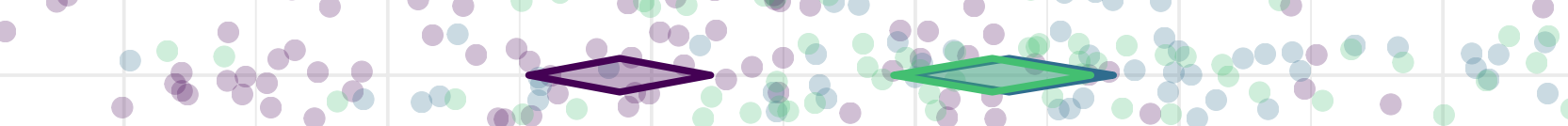

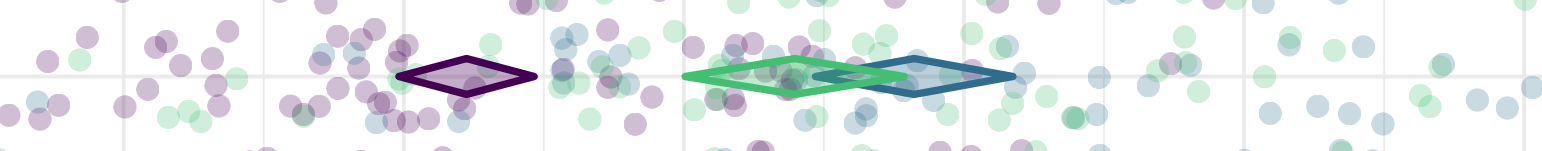

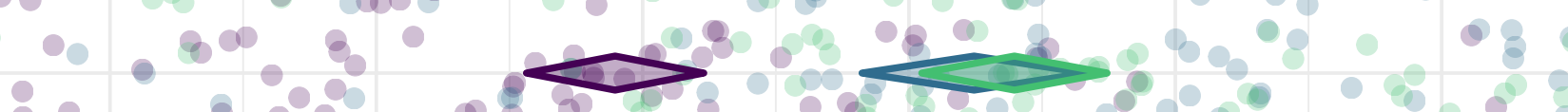

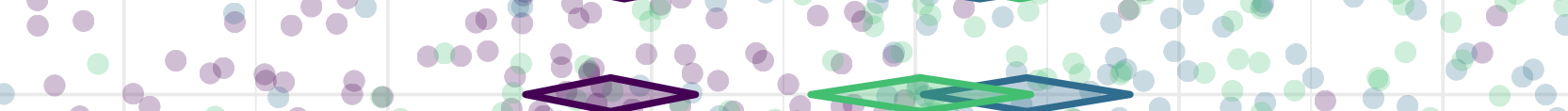

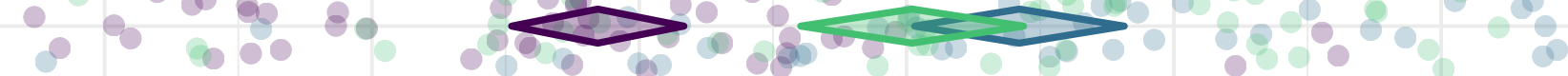

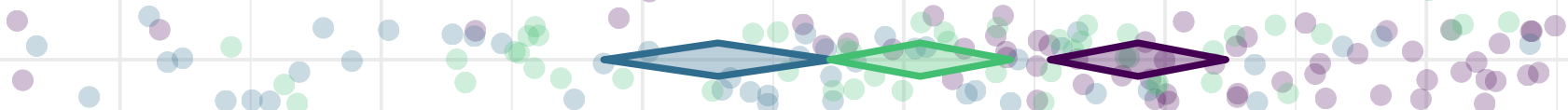

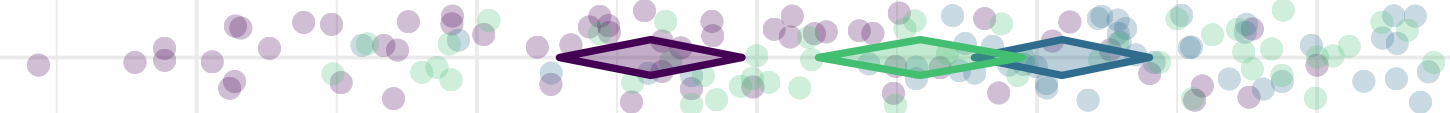

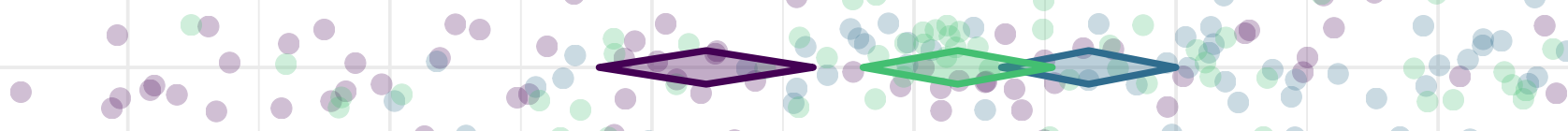

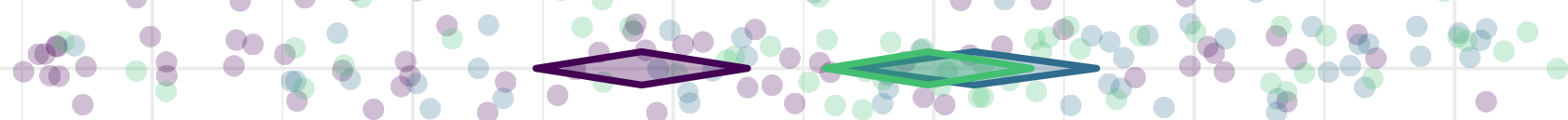

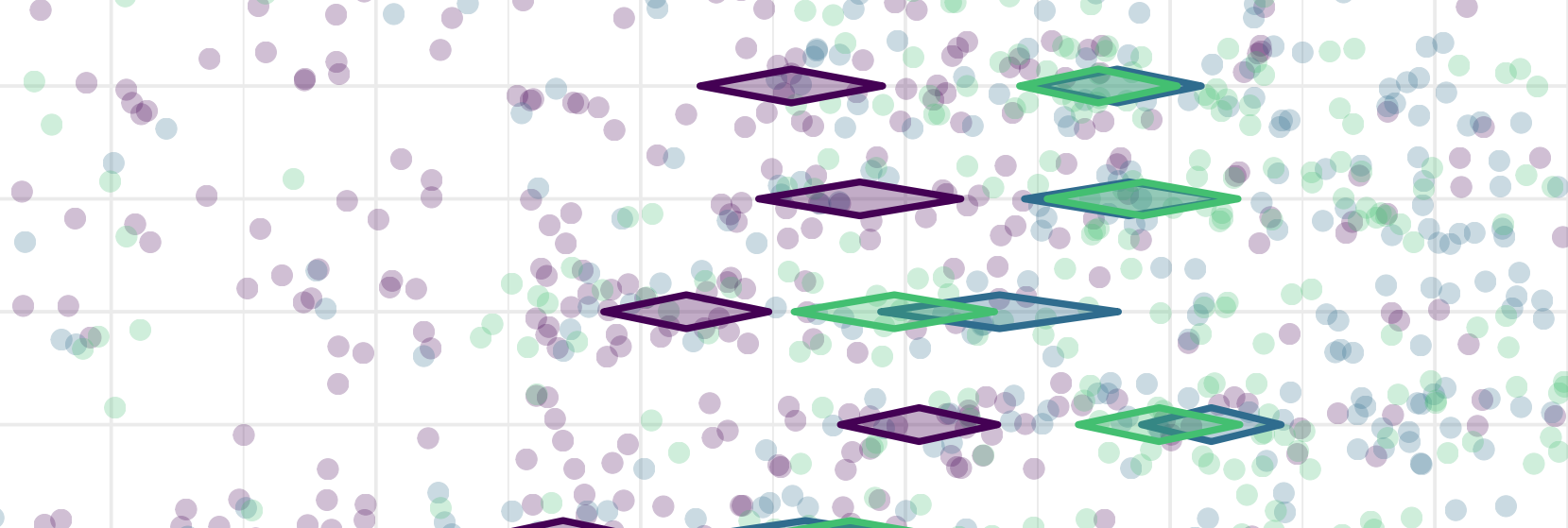

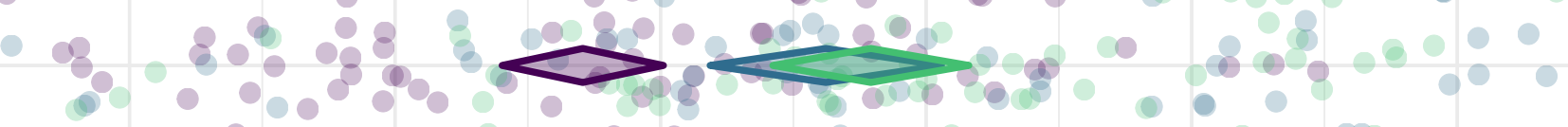
$\frac{0}{800} \frac{0}{20} 80_{0}^{\circ}, 8$

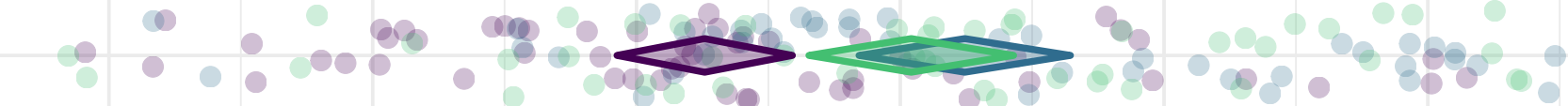

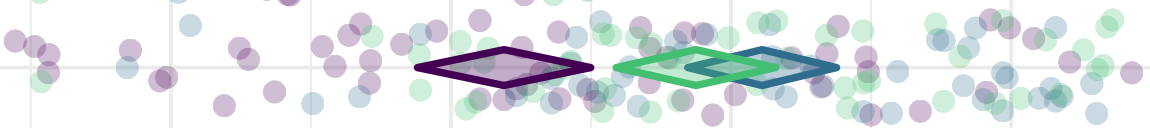

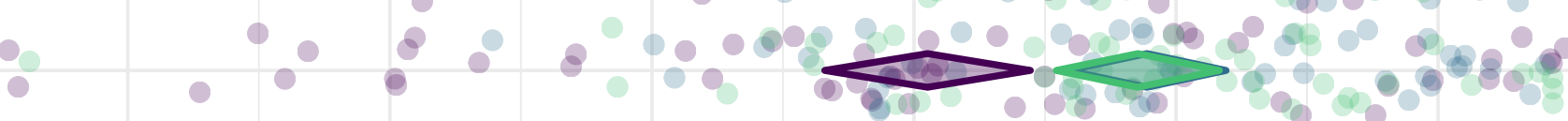
$000 \quad 0.000 \%$

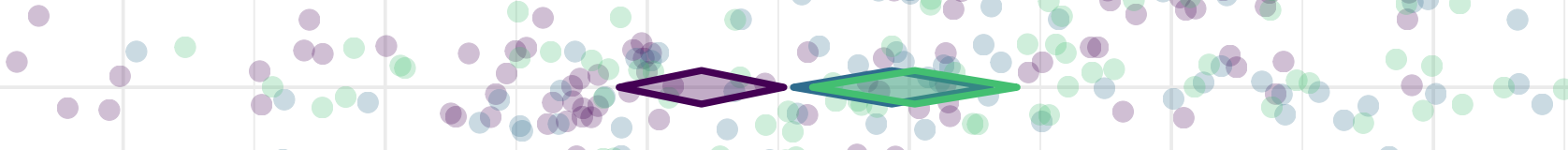

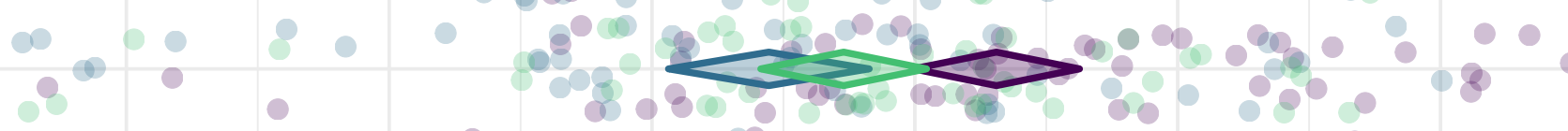

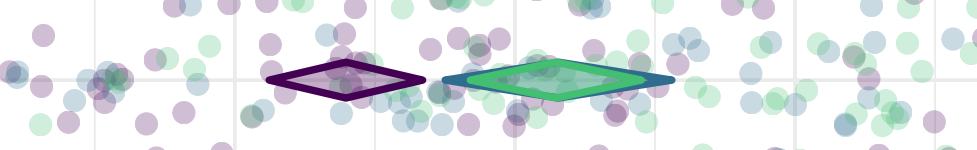
$38 \cdot 8 \sum_{0}$

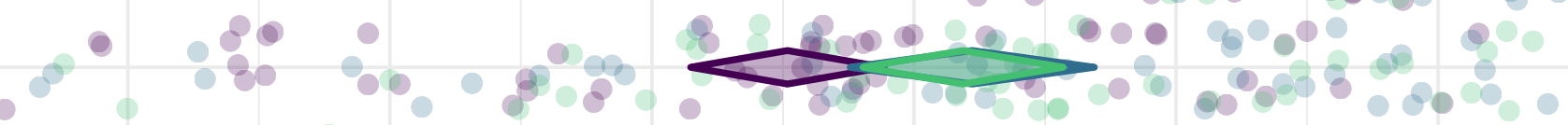

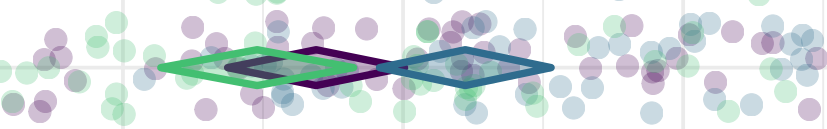

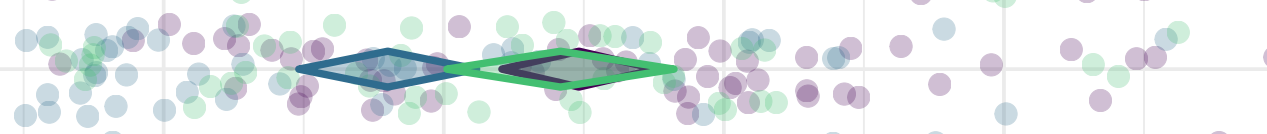

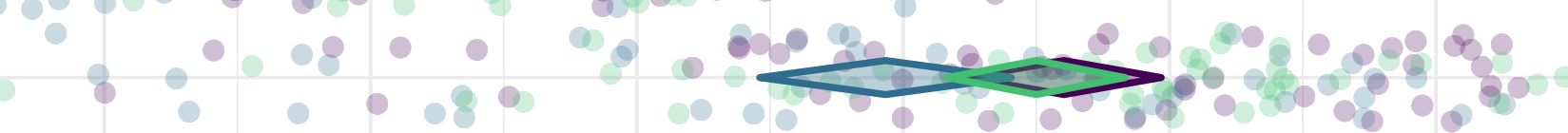

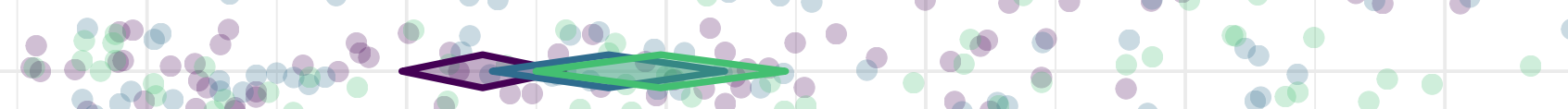

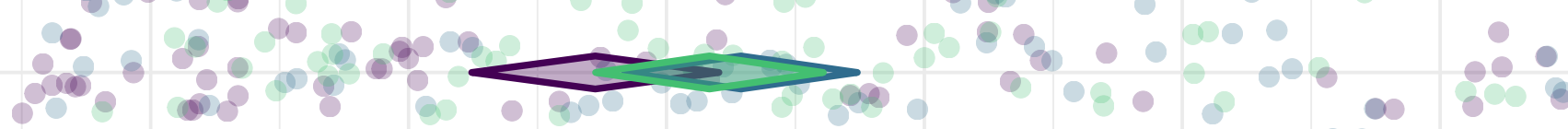

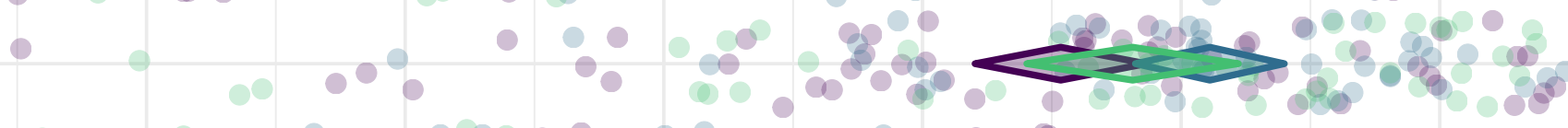

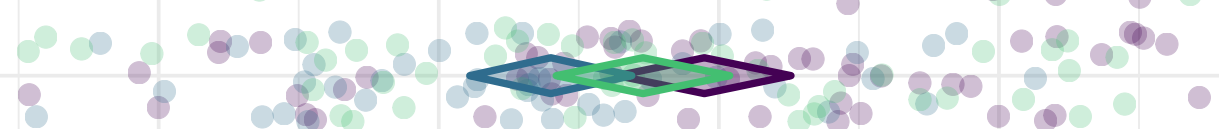

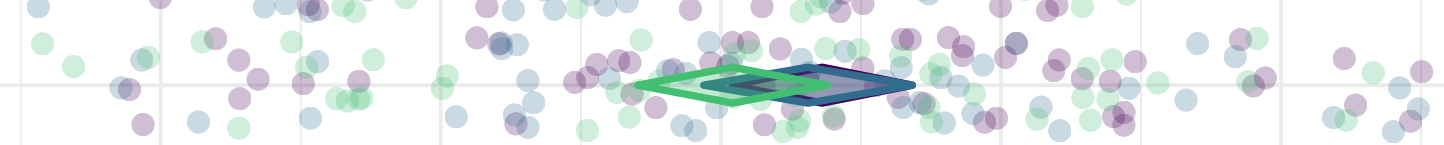

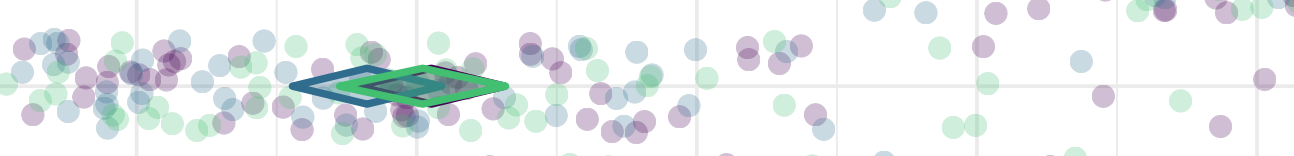

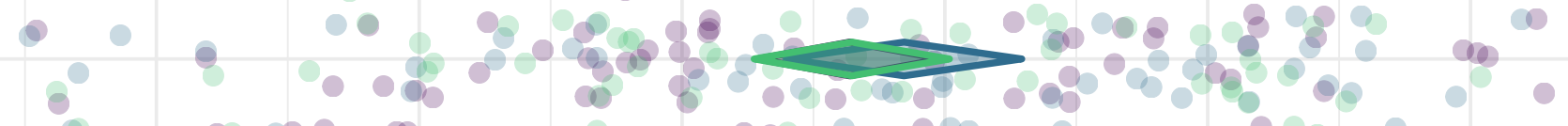

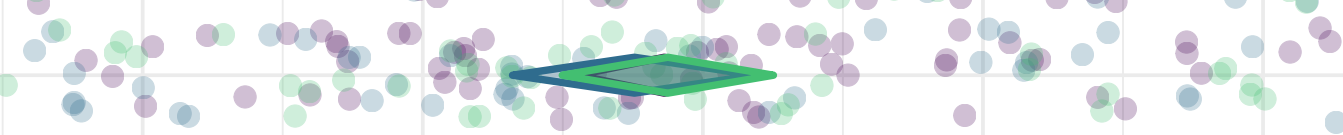

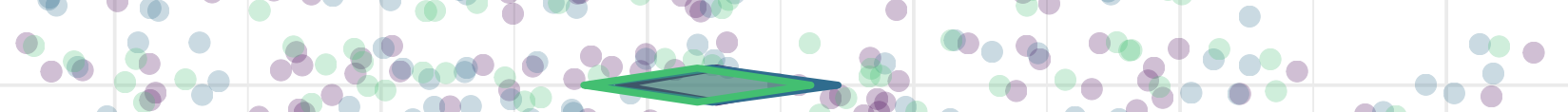









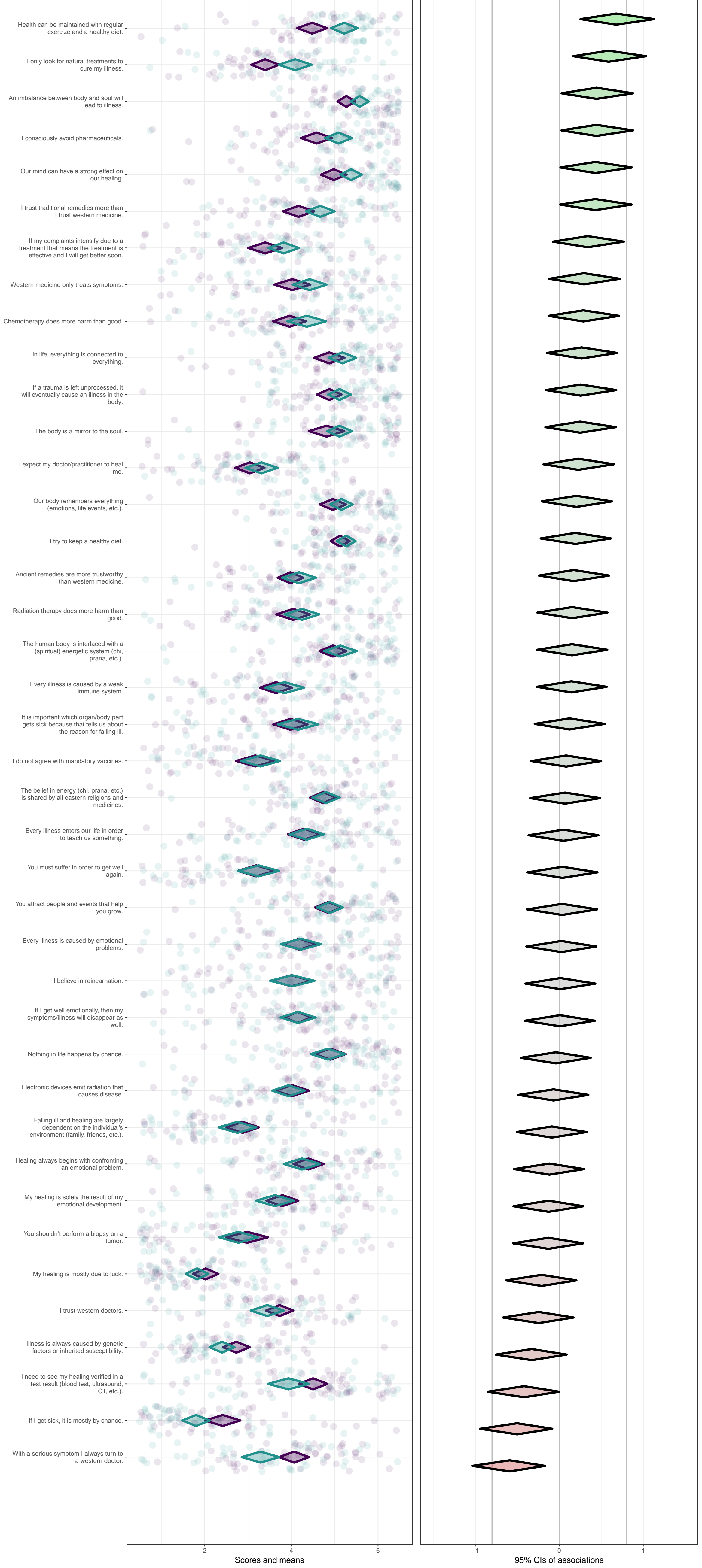

